\title{
The appearance of retinopathy and progression to proliferative retinopathy: the WHO multinational study of vascular disease in diabetes
}

\author{
H.Keen ${ }^{1}$, E.T. Lee ${ }^{2}$, D. Russell ${ }^{2}$, E.Miki ${ }^{3}$, P.H.Bennett ${ }^{4}$, M.Lu ${ }^{2}$ and the WHO Multinational Study Group* \\ ${ }^{1}$ Unit for Metabolic Medicine, Guy's Hospital, London, UK \\ ${ }^{2}$ Centre for American Indian Health Research and Department of Biostatistics and Epidemiology, College of Public Health, \\ University of Oklahoma Health Sciences Centre, Oklahoma City, USA \\ 3 3-4-2, Matsunami, Chuo-Ku, Chiba-Shi 260, Japan \\ ${ }^{4}$ Phoenix Epidemiology and Clinical Research Branch, NIDDK, Phoenix, Arizona, USA
}

\section{Abstract}

Aims/hypothesis. We aimed to estimate incidences of any retinopathy and proliferative diabetic retinopathy (PDR) by direct ophthalmoscopy and relate them to baseline risk factors in re-examined diabetic survivors from 10 centres of the WHO Multinational Study of Vascular Disease in Diabetes.

Methods. After a mean follow-up of 8.4 years (11.7 years in Oklahoma), 2877 (71.6\%) survivors were resubmitted to standardised direct ophthalmoscopy as at baseline. The presence of any retinopathy and PDR were recorded at each centre and their incidence estimated in those without retinopathy and PDR at baseline. The independent associations of these incidences with baseline risk factors are expressed as odds ratios derived from multiple logistic regression analyses, within individual centres (which included fasting plasma glucose in 8 and triglyceride in 5) and in pooled data.

Results. Of the 4662 original patients, 465 (10.4\%) of those without and $77(43.0 \%)$ of those with baseline PDR had died $(p<0.001)$. Any retinopathy was newly reported at follow-up in $47.7 \%$ and PDR in $9.7 \%$ of those free of them at baseline, with reported incidences varying substantially among centres. Incident retinopathy appeared earlier in the known course of diabetes but incidence rates rose more slowly with duration in patients with Type II (non-insulin-dependent) diabetes mellitus than in those with Type I (in- sulin-dependent) diabetes mellitus. In pooled data and in some individual centres, any retinopathy incidence gave significantly positive odds ratios with age, diabetes duration, systolic pressure, plasma cholesterol, BMI, insulin treatment and proteinuria, and with fasting plasma glucose in the centres where it was measured. Positive odds ratios for PDR were similarly obtained for age, duration, insulin treatment, cholesterol, proteinuria and fasting glycaemia. Smoking status odds ratios were negative for both outcomes.

Conclusion/interpretation. Incidence of ophthalmoscopically ascertained any retinopathy varied about twofold and of PDR about threefold among centres. Although, in part attributable to differences between observers, variation in incidence in all centres and in some cases within centres was associated with a number of baseline risk factors. Such associations are not likely due to observer variation or selection biases and emerged despite the imprecision of clinical ophthalmoscopy. Improved detection and control of these risk factors should reduce the impact of diabetic retinopathy and its consequences. [Diabetologia (2001) 44 [Suppl 2]: S22-S30]

Keywords Diabetic retinopathy, proliferative diabetic retinopathy, incidence, multinational study, risk factors, ethnic, arterial pressure, plasma glucose, plasma lipids, smoking.
Corresponding author: Prof H. Keen, Unit for Metabolic Medicine, Guy's Hospital Campus KCL, St Thomas' Street, London SE1 9RT, UK

* See Reference 13 for list of investigators
Abbreviations: PDR, Proliferative diabetic retinopathy; OR, odds ratio; NPDR, non-proliferative diabetic retinopathy; WHO MSVDD World Health Organization Multinational Study of Vascular Disease in Diabetes. 
This paper describes the incidence of newly reported, ophthalmoscopically detected diabetic retinopathy (any retinopathy) and appearance of proliferative diabetic retinopathy (PDR) in surviving patients at 10 of the original 14 WHO Multinational Study of Vascular Disease in Diabetes (WHO MSVDD) centres in which it was possible to carry out a systematic follow-up study [1]. It also considers, in these ethnically and geographically diverse diabetic populations, the relation between the incident events and biometric, clinical and biochemical factors recorded at baseline.

Vascular disease of the retina typifies the longterm diabetic state. It can ultimately be identified in virtually all people with Type I (insulin-dependent) diabetes mellitus and in a high proportion of those with Type II (non-insulin-dependent) diabetes mellitus. Diabetic retinopathy is usually present for many years before its progression to visual impairment and blindness makes it apparent to the patient. It is the leading cause of blindness in persons aged 25 to 74 years in the United States [2, 3] and in the United Kingdom the most common cause of blindness among people in their working years of life $[4,5]$.

It has been proposed that rates of diabetic microangiopathy vary less among diverse ethnic and geographical diabetic groups [9] than rates of macrovascular (atherosclerotic) disease which differs widely in its impact in those without [6] and with diabetes $[7,8,14]$. The prevalence study of the WHO MSVDD gave some support to this hypothesis $[10,11,12]$ and is reconsidered in relation to our incidence findings.

The WHO MSVDD was started in the mid-1970's at a time when the skills and standards for retinal photography were yet to be established and retinal cameras were not widely available. Since clinical ophthalmoscopy was, and in many centres still is, the principal method for detecting diabetic retinopathy, the study was carried out by local, trained observers using direct ophthalmoscopy through dilated pupils and working to an agreed, standardised protocol for examination and objective documentation. Even with such standardisation, this method will inevitably introduce some bias and variation into results due to differences between observers. Epidemiological studies to date would use more objective, verifiable and precise centrally-read retinal photographic records. The major justification for including this 'historical' study lies not so much in the differences in reported retinopathy incidence between centres as in the sometimes highly significant associations between a number of baseline characteristics and retinopathy incidence which emerged in pooled data and sometimes in individual centres in spite of the sources of imprecision noted above.

\section{Subjects and methods}

Of the 4662 patients in the 10 centres who underwent standardised direct ophthalmoscopic retinal examination in the baseline prevalence study, $3140(67.4 \%)$ were reported free from retinopathy, 1343 (28.8\%) with non-proliferative diabetic retinopathy (NPDR) and $179(3.8 \%)$ with proliferative diabetic retinopathy (PDR). This report concerns the findings in the 2877 survivors $(71.6 \%)$ of those free of PDR at baseline who were subjected to ophthalmoscopic re-examination at followup, using the baseline protocol.

Analysis of incidence was restricted to new reports of any retinopathy or of PDR when these were reported respectively as absent at baseline. This simple analytical approach further acknowledges the limitations of direct ophthalmoscopy for more precise quantitative epidemiological estimates of worsening, such as those made possible by the photographic methods now in use. Analytical groupings, definitions of retinopathy and baseline variables and the statistical methods used have been described in detail $[12,13]$. In every centre, the presence of non-proliferative retinopathy at baseline was a strong $(p<0.01)$ univariate predictor of incident PDR (data not shown) and was not included in multivariate analysis because of its close aetiological relation. Fasting plasma glucose was measured at baseline at 8 of the 10 follow-up centres and triglycerides at 5 of these. A $p$ value of less than 0.05 was considered statistically significant.

\section{Results}

The composition of the patient group is shown in Table 1 . Of the 4662 patients whose eyes were examined at baseline, 4483 were reported free of PDR and 3140 free of any retinopathy. During the follow-up period, $465(10.4 \%)$ of the patients free of PDR died compared with $77(43.0 \%)$ of the 179 patients with PDR at baseline $(p<0.001)$.

Of the 4018 survivors free of PDR at baseline, $2877(71.6 \%)$ were re-examined ophthalmoscopically at follow-up according to the original protocol. Of these, $2108(73.3 \%)$ had been free of retinopathy and $769(26.7 \%)$ had NPDR at baseline. Follow-up time for participants was between 7 and 9 years (mean 8.4 years) at all centres except Oklahoma where it averaged 11.7 years. Oklahoma and Zagreb lost a higher proportion of patients to follow-up eye examination than other centres.

Retinopathy incidence. At follow-up re-examination, the presence of incident any retinopathy was recorded in $1006(47.7 \%)$ of the 2108 reported as retinopathy-free at baseline (Table 2).

Cumulative incidence of any retinopathy was highest in Oklahoma $(76.4 \%)$ where follow-up time was almost $40 \%$ longer than the average (Table 2). Rates were also high in Zagreb (73.1\%) and Hong Kong $(58.1 \%)$. The lowest recorded incidence was in Tokyo $(29.7 \%)$. When separated into the clinical types of diabetes, although there was a higher incidence of any retinopathy in Type I than Type II diabetic pa- 
Table 1. Follow-up status of patients free of PDR at baseline

\begin{tabular}{|c|c|c|c|c|c|c|c|}
\hline \multicolumn{2}{|l|}{ Baseline } & \multicolumn{6}{|c|}{ Follow-up status } \\
\hline \multirow[b]{2}{*}{ Centre } & \multirow[b]{2}{*}{$n$} & \multicolumn{2}{|c|}{ Re-examined participants } & \multicolumn{2}{|c|}{ Deceased } & \multicolumn{2}{|c|}{ Surviving non-participants } \\
\hline & & $n$ & $\%$ & $n$ & $\%$ & $n$ & $\%$ \\
\hline Switzerland & 491 & 346 & 70.5 & 44 & 9.0 & 101 & 20.6 \\
\hline Warsaw & 464 & 312 & 67.2 & 74 & 15.9 & 78 & 16.8 \\
\hline Berlin & 532 & 322 & 60.5 & 69 & 13.0 & 141 & 26.5 \\
\hline Tokyo & 401 & 287 & 71.6 & 18 & 4.5 & 96 & 23.9 \\
\hline Havana & 499 & 330 & 66.1 & 57 & 11.4 & 112 & 22.4 \\
\hline Oklahoma & 620 & 301 & 48.5 & 81 & 13.1 & 238 & 38.4 \\
\hline Arizona & 229 & 168 & 73.4 & 15 & 6.6 & 46 & 20.1 \\
\hline Total & 4483 & 2877 & 64.2 & 465 & 10.4 & 1141 & 25.4 \\
\hline
\end{tabular}

Table 2. Cumulative incidence of retinopathy by centre

\begin{tabular}{|c|c|c|c|c|c|c|}
\hline \multirow[b]{3}{*}{ Centre } & \multicolumn{3}{|c|}{ Any retinopathy } & \multicolumn{3}{|l|}{ PDR } \\
\hline & \multirow{2}{*}{$\begin{array}{c}\text { At risk } \\
n\end{array}$} & \multicolumn{2}{|l|}{ Incidence } & \multirow{2}{*}{$\begin{array}{c}\text { At risk } \\
n\end{array}$} & \multicolumn{2}{|l|}{ Incidence } \\
\hline & & $n$ & $(\%)$ & & $n$ & $(\%)$ \\
\hline Switzerland & 241 & 102 & 42.3 & 346 & 42 & 12.1 \\
\hline Warsaw & 211 & 67 & 31.8 & 312 & 11 & 3.5 \\
\hline Berlin & 231 & 69 & 29.9 & 322 & 34 & 10.6 \\
\hline Tokyo & 192 & 57 & 29.7 & 287 & 23 & 8.0 \\
\hline Havana & 265 & 120 & 45.3 & 330 & 20 & 6.1 \\
\hline Oklahoma $^{\mathrm{a}}$ & 275 & 210 & 76.4 & 301 & 45 & 15.0 \\
\hline Arizona & 128 & 61 & 47.7 & 168 & 15 & 8.9 \\
\hline Total & $2108(1833)^{b}$ & $1006(796)^{b}$ & $47.7(43.4)^{\mathrm{b}}$ & $2877(2576)^{b}$ & $279(234)^{b}$ & $9.7(9.1)^{\mathrm{b}}$ \\
\hline
\end{tabular}

a Average follow-up in Oklahoma was 11.7 years compared with 8.4 years in other centres

${ }^{\mathrm{b}}$ Excluding Oklahoma

tients in Switzerland, Berlin, Tokyo and Havana (Fig. 1,2), the pooled incidences did not differ significantly. Pooled PDR incidence was, however, higher in those with Type I $(14.6 \%)$ than in those with Type II $(8.0 \%)$ diabetes $(p<0.01)$.

Any retinopathy incidence and baseline variables. Mean values of baseline variables in those reported to be without retinopathy at that time were calculated for those who had developed any retinopathy at follow-up and for those who had not (Table 3). Systolic pressure, BMI, cholesterol, triglyceride and fasting glucose were all higher at baseline in those with incident retinopathy at follow-up.

Stepwise logistic regression analysis. Odds ratios (OR) were calculated from the regression coefficients in stepwise logistic regression analyses, with incident any retinopathy as the dependent variable and entering all the variables listed in Table 4 into the regression equations. These were selected as factors significantly related to retinopathy incidence in simple bivariate analysis in individual centres and/or pooled data. Ratios are based on specified increments (units of change) in, or for stated categories of, the independent variables.

Although the incidence of any retinopathy in the pooled data was higher in women $(51.1 \%)$ than in men $(44.7 \% p<0.003)$, the OR for sex failed to achieve significance in the multivariable analysis, suggesting that the sex difference was explained by other variables. Odds ratios for baseline age, systolic and diastolic blood pressure, cholesterol, BMI, insulin treatment and proteinuria were statistically significant for incident retinopathy in pooled data and in some individual centres. Known duration of diabetes though positive in 3 centres was not significant in pooled data. Incident retinopathy appeared earlier but rose more slowly with increasing duration from diagnosis in Type II than in Type I diabetic patients (Fig. 3).

Significant ORs after adding baseline fasting plasma glucose into the model for the 8 centres in which it was measured are listed in Table 5. ORs for fasting plasma glucose were highly significant for retinopathy in pooled data and in 6 of the 8 individual centres 
Type I (insulin-dependent) diabetes mellitus

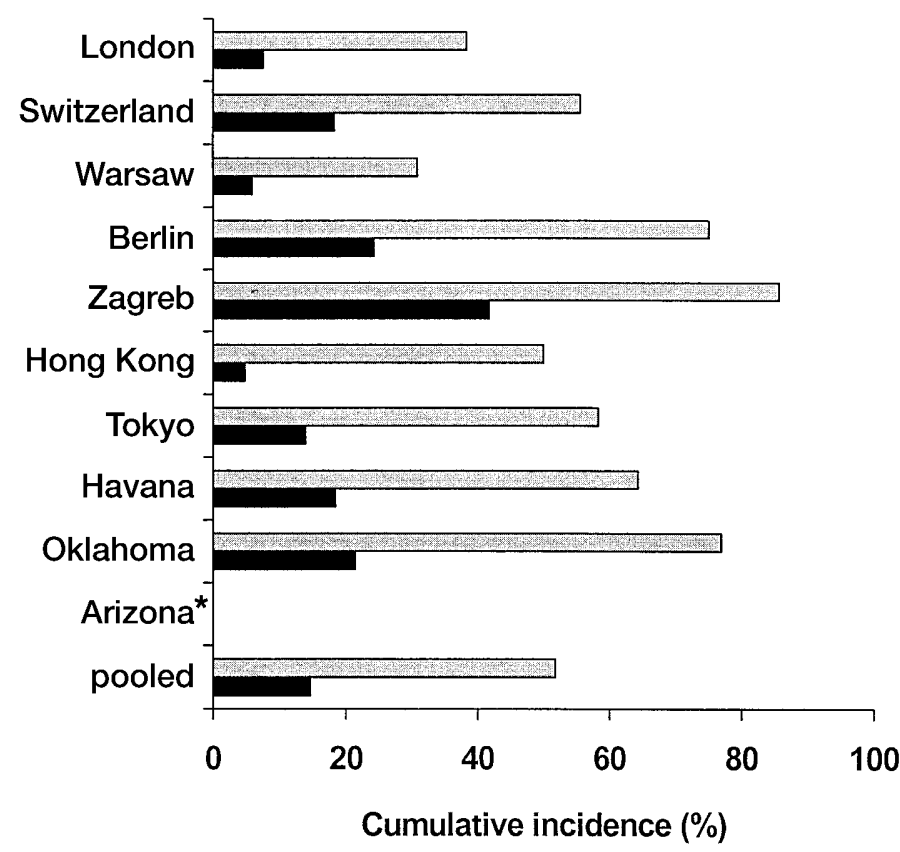

Fig. 1. Cumulative incidence (\%) of any retinopathy and PDR by type of diabetes in the 10 participating centres individually and pooled data. PDR, $\mathbf{\square}$; any retinopathy,

* No Type I diabetes in Arizona centre

(Table 5). Fasting triglycerides were unrelated (data not shown).

PDR incidence and baseline variables. Proliferative diabetic retinopathy was reported at follow-up in 279 $(9.7 \%)$ of the 2877 patients free of it at baseline. Of those developing PDR, 157 (56.4\%) were identified by the appearance of new vessels, $90(32.2 \%)$ by photocoagulation treatment and $32(11.5 \%)$ by vitreous haemorrhage. In pooled data, there was no significant difference in PDR incidence between the sexes but it was higher in patients with Type I $(14.8 \%)$ than in those with Type II $(8.0 \%, p<0.01$, Fig. 1,2$)$.
Type II (non-insulin-dependent) diabetes mellitus

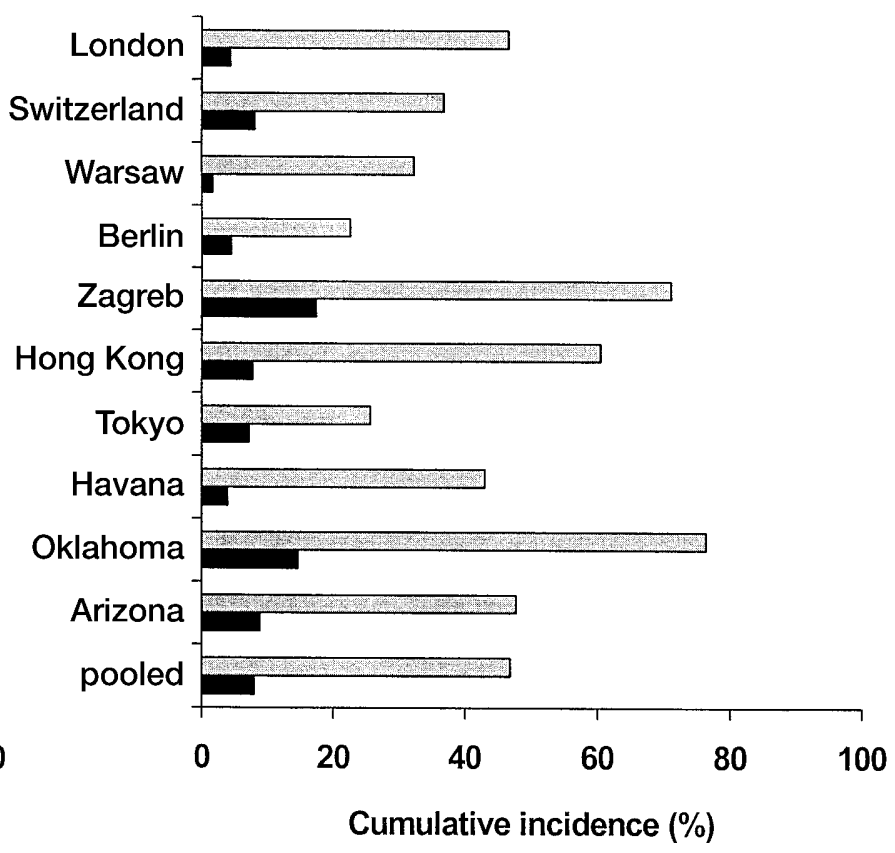

Stepwise logistic regression analysis. Odds ratios were significant for age and for known diabetes duration in pooled data and some individual centres (Table 6); as with any retinopathy, PDR appeared earlier in Type I than Type II diabetic patients but later incidence rose more slowly (Fig.3). Significant ORs were also found for plasma cholesterol, insulin treatment and proteinuria at baseline; for age and smoking status ORs favoured the older patients and the smokers (Table 6). Few of these ratios were statistically significant in individual centres where incident events of PDR were relatively few in number. Fasting plasma glucose introduced into the model in the 8 centres (Table 7) generated highly significant ORs for PDR in pooled data and in the individual centres listed in Table 6 which also lists other ORs significant after adding fasting glucose to the regression equations.

Table 3. Mean values of metabolic variables at baseline in those without (no) and with (yes) incident retinopathy at follow-up

\begin{tabular}{llllll}
\hline Variable & Incident Retinopathy & $n$ subjects & Mean & SD of mean & $p$ no vs yes \\
\hline Cholesterol mmol/l & - & no 1027 & 5.47 & 1.75 & 0.0001 \\
& + & yes 922 & 5.79 & 1.73 & \\
Triglyceride* mmol/l & - & no 477 & 1.7 & 1.1 & 0.0001 \\
& + & yes 431 & 2.3 & 2.7 & \\
F. glucose* mmol/l & - & no 752 & 8.2 & 3.7 & 0.0001 \\
& + & yes 602 & 11.2 & 4.4 & \\
BMI Kg/m & - & no 1040 & 27.1 & 5.7 & 0.0002 \\
& + & yes 987 & 28.1 & 6.0 & \\
\hline
\end{tabular}

* Fasting plasma glucose was measured in 8 centres viz: London, Switzerland, Warsaw, Berlin, Tokyo, Havana, Oklahoma, Arizona and triglycerides in 5 centres viz: London, Switzerland, Warsaw, Berlin, Oklahoma 
Type I (insulin-dependent) diabetes mellitus

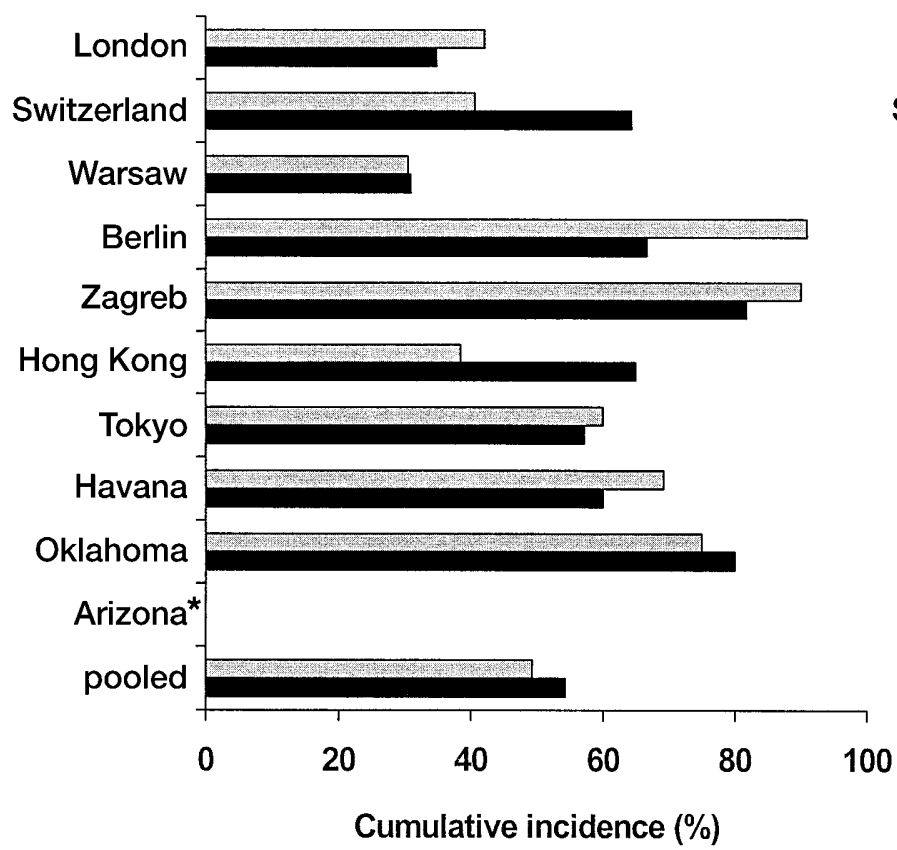

Fig. 2. Cumulative incidence (\%) of any retinopathy and PDR by sex and type of diabetes. Women, $\mathbf{\square}$; Men,

* No Type I diabetes in Arizona centre

\section{Discussion}

Retinopathy - incidence estimates and sources of error. Retinopathy incidences were based on locally conducted, direct ophthalmoscopic re-examination of $71.6 \%$ of the 4018 participants, surviving and free of PDR at baseline, from 10 of the original 14 centres of the WHO MSVDD, using the same examination protocol as at baseline. There is no information on the follow-up retinal status of the non-participating survivors nor of the 542 patients who died during follow-up.
Type II (non-insulin-dependent) diabetes mellitus

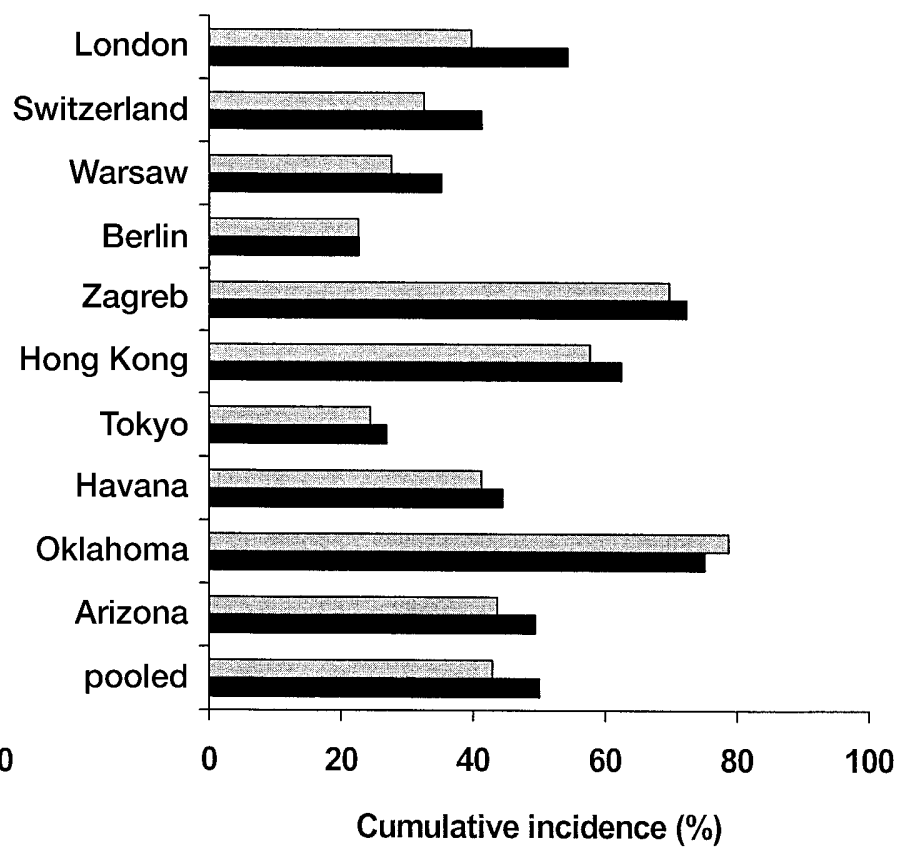

Mortality was fourfold higher in those with PDR at baseline than in those without $(p<0.001)$, confirming its serious prognostic significance as documented in other studies [15, 35, 36]. A greater proportion of the other decedents were men, with longer duration of diabetes, higher systolic and diastolic pressures, higher plasma cholesterol, and more of them insulin users. These baseline risk factors also, but less markedly, characterised the 1141 non-participating survivors. This paper is therefore likely to provide a low estimate of true incidence.

Direct ophthalmoscopy as used in this study is less sensitive and specific than the retinal photographic methods which have come to be the 'gold standard' for epidemiological surveys of diabetic retinopathy $[22,37]$. To optimise comparability, our fundus examinations were carried out by skilled and experienced

Table 4. Odds ratios of baseline variables associated with any retinopathy

\begin{tabular}{|c|c|c|c|c|c|c|c|c|c|c|c|}
\hline $\begin{array}{l}\text { Baseline Variable } \\
(\mathrm{u} \text { of } \mathrm{c})\end{array}$ & London & $\begin{array}{l}\text { Switzer- } \\
\text { land }\end{array}$ & Warsaw & Berlin & Zagreb & $\begin{array}{l}\text { Hong } \\
\text { Kong }\end{array}$ & Tokyo & Havana & $\begin{array}{l}\text { Okla- } \\
\text { homa }\end{array}$ & Arizona & Pooled \\
\hline $\operatorname{Sex}^{\mathrm{a}}$ & 0.82 & 0.91 & 1.01 & 1.09 & 0.98 & 0.61 & 0.60 & 1.10 & 1.28 & 0.82 & 0.88 \\
\hline Age (5 years) & 0.97 & 0.89 & 1.16 & 0.89 & 0.82 & 1.07 & $0.69 *$ & 0.94 & 0.86 & 0.96 & $0.91 *$ \\
\hline Systolic BP (10 mm Hg) & 1.07 & 1.19 & 1.18 & 1.01 & $1.40^{*}$ & 1.06 & 0.91 & 1.06 & $1.42 *$ & 1.16 & $1.11 * *$ \\
\hline Diastolic BP (5 mm Hg) & 0.96 & 0.95 & 1.02 & 1.04 & 0.93 & 1.14 & 1.13 & 1.01 & 0.96 & 0.98 & $0.94 *$ \\
\hline Plasma cholesterol $(10$ mg/dl $)$ & 0.99 & 1.04 & 0.99 & 1.00 & 1.00 & 0.98 & 1.07 & 1.01 & 1.05 & 1.07 & $1.03 * *$ \\
\hline Insulin treatment ${ }^{\mathrm{b}}$ & 1.61 & 1.40 & $3.05^{*}$ & $4.20 *$ & 4.55 & 1.29 & $3.89 *$ & $4.04 *$ & 1.15 & 0.72 & $1.64 * *$ \\
\hline Macro vascular disease ${ }^{b}$ & 0.81 & 1.19 & 0.66 & 1.13 & 0.41 & 1.04 & 1.13 & 1.47 & 0.83 & 0.95 & 0.92 \\
\hline Renal disease ${ }^{b}$ & 1.44 & 1.57 & 1.04 & 0.92 & 1.05 & 0.82 & 1.78 & $2.94 *$ & 1.55 & 4.65 & $1.28^{*}$ \\
\hline Type of diabetes ${ }^{c}$ & 0.53 & 2.70 & 0.71 & 1.61 & 0.41 & 0.58 & 1.08 & 0.16 & 1.73 & - & 0.92 \\
\hline Sex by type of diabetes ${ }^{c}$ & 2.34 & 0.40 & 1.44 & 4.76 & 2.21 & 0.74 & 2.74 & 3.55 & 0.17 & - & 1.15 \\
\hline
\end{tabular}

$(\mathrm{u}$ of $\mathrm{c})=$ units of change $* p<0.05 ;{ }^{* *} p<0.01$; ${ }^{\mathrm{a}} 0$-female, 1 -male; ${ }^{\mathrm{b}} 0=$ no, $1=$ yes; ${ }^{\mathrm{c}} 0=$ Type II, $1=$ Type I diabetes 
Type I (insulin-dependent) diabetes mellitus

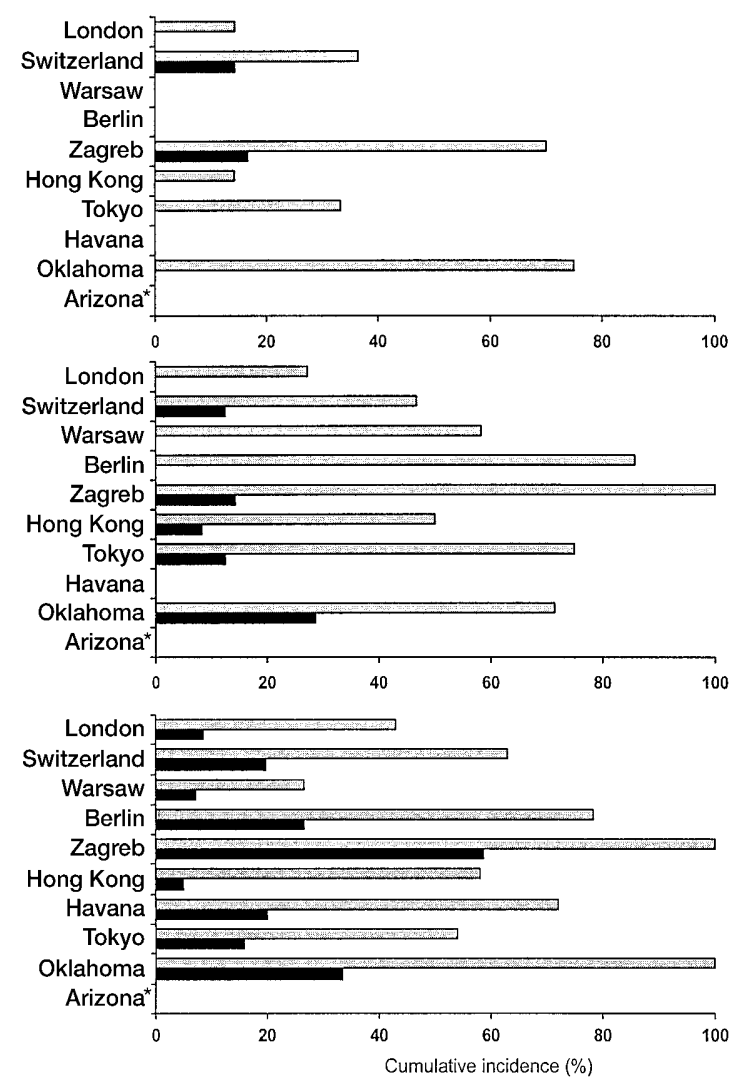

Type II (non-insulin-dependent) diabetes mellitus

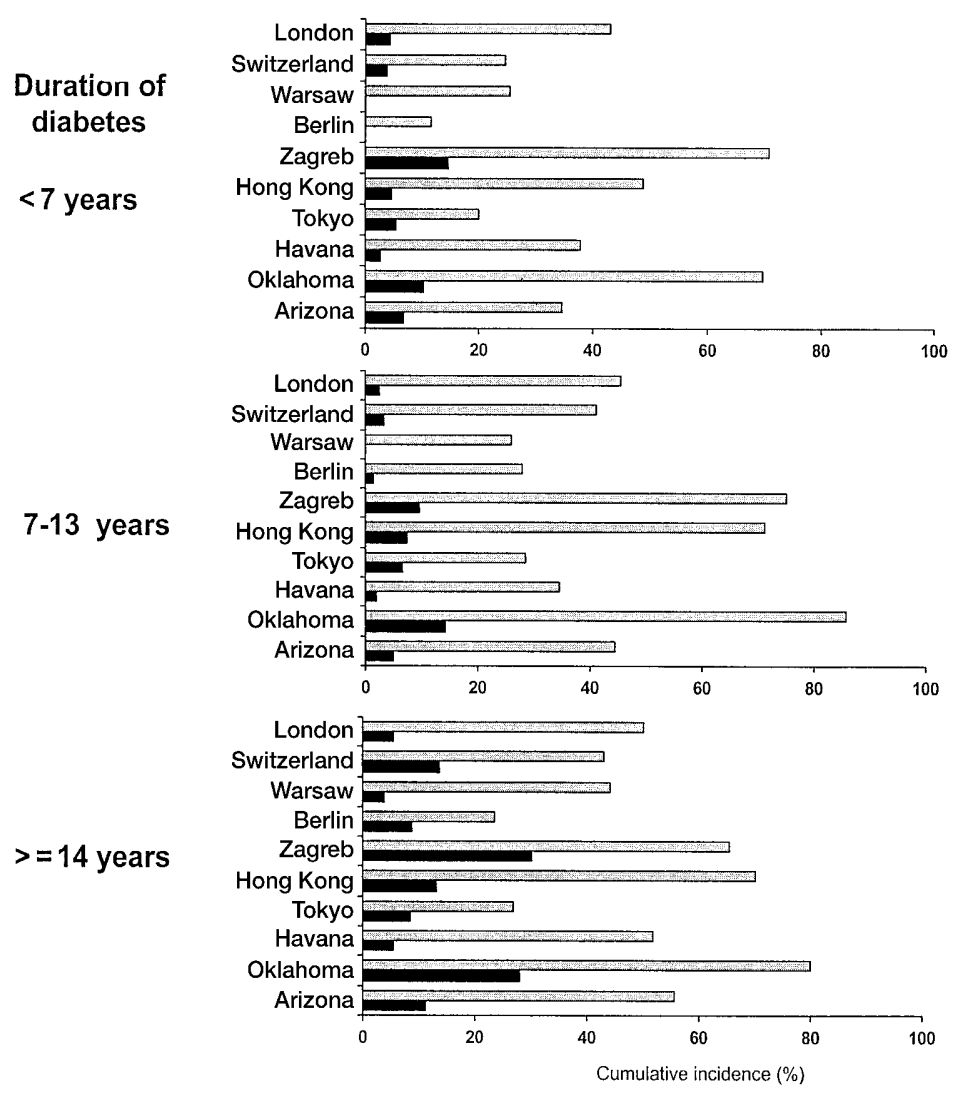

Fig. 3. The effect of duration on cumulative incidence (\%) of any retinopathy and PDR in Type I and Type II diabetic patients. PDR, $\mathbf{\square}$; any retinopathy,

* No Type I diabetes in Arizona centre

local professionals, its methodology was specified in detail, and abnormalities found were documented using a simple, interpretation-free description of lesions [12]. Finally, the incidences reported were restricted simply to the qualitative documentation of the appearance of any retinopathy and of PDR. No attempt was made to quantitate lesser degrees of retinopathy progression, now possible with retinal photographs. Estimates of incidence are, nevertheless, likely to have been influenced by systematic differences between examiners in individual centres so that direct comparisons of rates between centres must be guarded. The use of the less precise method of direct ophthalmoscopy is, however, more likely to have obscured rather than to have created the statistical associations we observed between retinopathy incidence and baseline risk factors. This lower precision could account, at least in part, for associations statistically significant in pooled data but not in the smaller numbers in individual centres.

Table 5. Any retinopathy. Significant odds ratios with fasting plasma glucose included

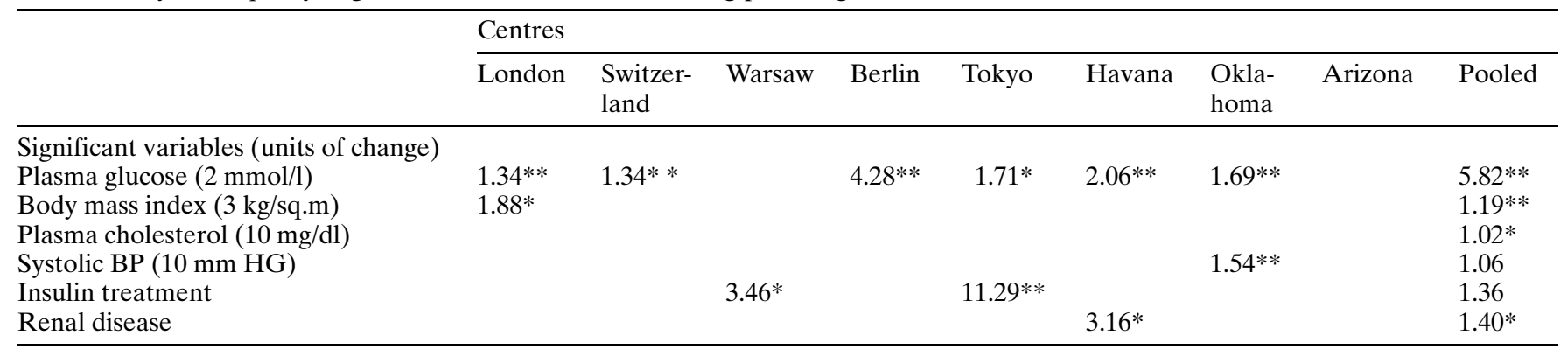

$* p<0.05 ; * * p<0.01$ 
Table 6. Odds ratios of variables associated with incident PDR

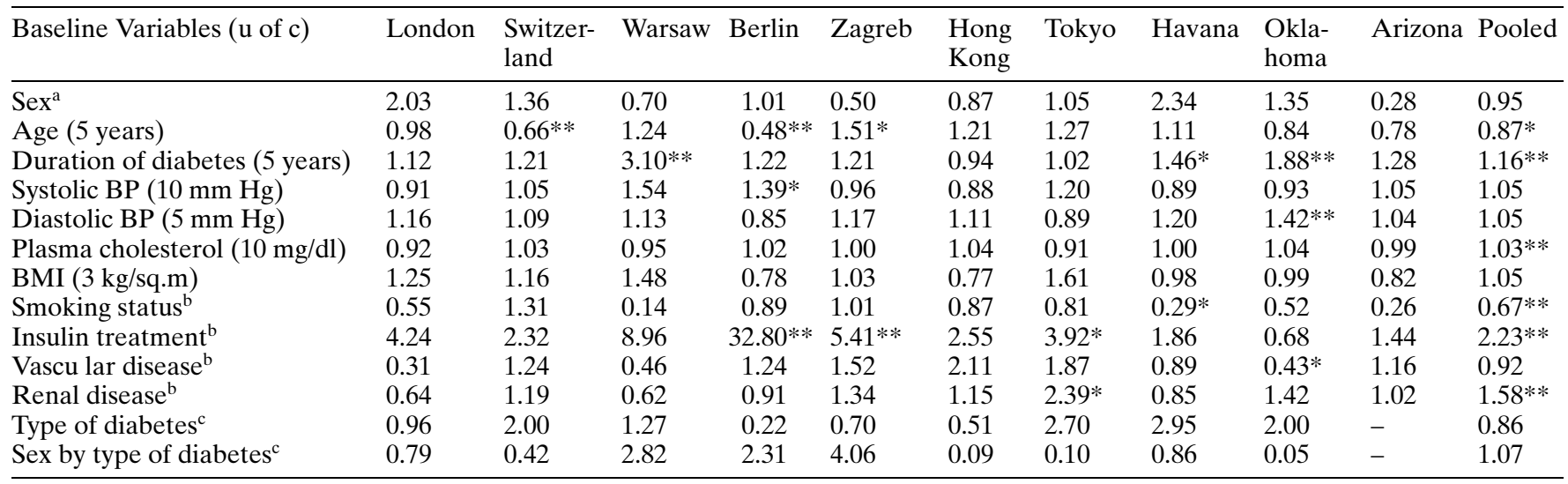

$(\mathrm{u}$ of $\mathrm{c})=$ units of change $* p<0.05 ;{ }^{*} p<0.01 ;{ }^{\mathrm{a}} 0$-female, 1 -male; ${ }^{\mathrm{b}} 0=$ no, $1=$ yes; ${ }^{\mathrm{c}} 0=$ Type II, $1=$ Type I diabetes

Table 7. PDR. Significant odds ratios with fasting plasma glucose incuded

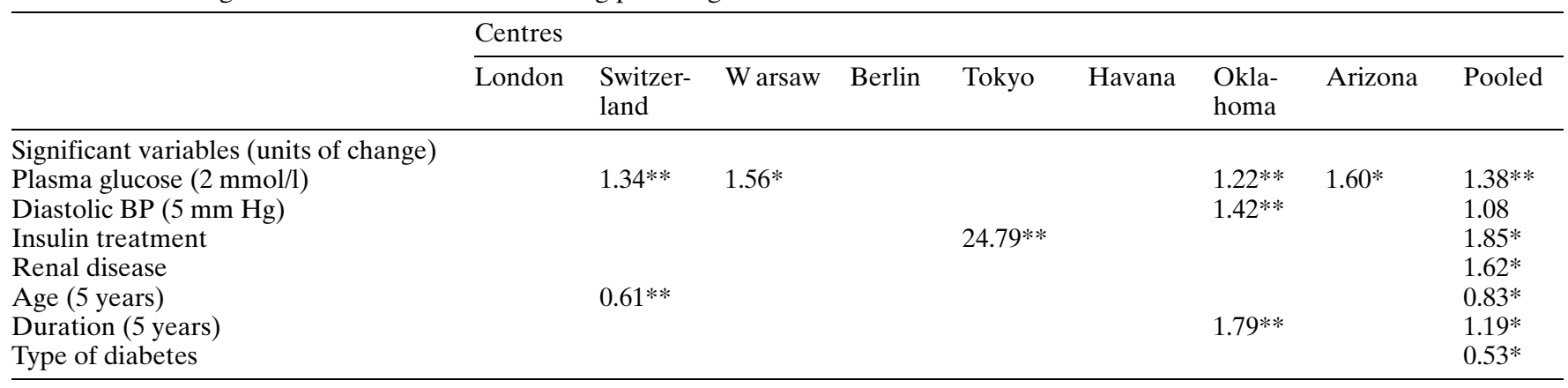

$* p<0.05 ; * * p<0.01$

Incidence rates. Retinopathy is already present in up to $20 \%$ of those with newly diagnosed Type II diabetes $[17,18,19,20,38]$, strongly suggesting substantial prior periods of unrecognised diabetes. Variation in the availability of medical services and attitudes to diabetes screening in the WHO MSVDD centres could thus have been a factor in the duration of unrecognised Type II diabetes and consequently the proportion with complications present at diagnosis or appearing soon after. Rates of PDR reported could also have been influenced by varying indications for and access to photocoagulation. In Hong Kong and Havana, no PDR was ascribed to this treatment, while the proportion identified by new vessel formation varied from $32 \%$ in Berlin to $81 \%$ in Switzerland.

With the exception of the higher rates in Oklahoma (where follow-up was 3.6 years longer than average) and Zagreb, estimates of incidence rates of any retinopathy in the individual centres varied relatively little around the overall average rate of $43 \%$, about $5 \%$ a year. Estimates of PDR incidences, which varied more in relative terms around a much lower overall mean of $9 \%$ (about $1 \%$ a year), were also high in Oklahoma and Zagreb. Using retinal photographic ascer- tainment of retinopathy in a US diabetic population [39], other investigators reported an overall 10-year incidence of any retinopathy of $89.3 \%$ in insulin-treated patients with diabetes diagnosed before the age of 30 years, $79.2 \%$ in insulin-treated patients diagnosed after the age of 30 and $66.9 \%$ in patients older than 30 years treated without insulin [39]. Corresponding 10 year incidence rates for PDR were $29.8 \%, 23.6 \%$ and $9.7 \%$ respectively. Probably due to the greater sensitivity of the photographic methods used, these rates are higher than those reported here and also higher than those recorded in the University Group Diabetes Program [40] and other rates reported elsewhere in a review of published studies on retinopathy incidence [41]. In these other studies, as in this report, incidence rates of PDR in Type I diabetes are twice or more those in Type II diabetes.

Baseline predictors of retinopathy. It is a measure of the importance of glycaemic control as a predictor of risk that, in the centres where it was measured, even the one fasting blood glucose estimation at baseline emerged as the single most powerful independent predictor of the incidence of any retinopathy and PDR. 
The strong association between degree of hyperglycaemia and the appearance and progression of retinopathy has been observed in many studies based on clinical patient groups, particularly since the introduction of glycated haemoglobin as a measure of glycaemic control [22, 23, 38, 42, 46, 48]. The Wisconsin Epidemiologic Study of Diabetic Retinopathy [39, 43] showed the predictive importance of $\mathrm{HbA}_{1 \mathrm{c}}$ in a population-based, prospective study in the United States. The close, probably causal nature of this link has most recently been affirmed in Type I diabetes by the Stockholm study [44], in the Diabetes Control and Complications Trial [45] and in Type II diabetes by the Japanese [46] and the United Kingdom Prospective Diabetes Study [47]. In our study, the higher retinopathy incidence in Type I than Type II diabetic patients was associated with a higher mean fasting plasma glucose with concentrations of 11.2 and $8.8 \mathrm{mmol} / 1$ respectively $(p<0.001)$.

Raised systolic pressure at baseline was a predictor of any retinopathy incidence. The role of arterial hypertension as a risk factor for diabetic microvascular disease in Type II diabetes was apparent in the United Kingdom Prospective Diabetes Study [48] which also provided evidence that, in those with raised pressures, the appearance and progression of retinopathy could be slowed by effective antihypertensive and antidiabetic treatment [49]. The absence of a statistically significant association of baseline arterial pressure with PDR incidence should be considered in the light of the relatively small number of incident events, the limitations of a single blood pressure measurement made up to 10 years earlier or the more dominant role of hyperglycaemia and advancing retinal ischaemia as determinants of the later proliferative stages of retinopathy evolution.

The Early Treatment of Diabetic Retinopathy study documented the much greater risk of progression to PDR in patients with pre-existing retinopathy, and it also showed that photocoagulation treatment reduced the rate of progression to PDR and visual impairment [50]. The effect of tobacco smoking on diabetic retinopathy has long been contested [30, 31]. In our study there was some indication that smokers had a lower risk of the first appearance of any retinopathy and progression to PDR compared to nonsmokers, an apparent advantage which disappeared when blood glucose was included in the analyses.

In conclusion, the multinational follow-up study gives limited and qualified support to an earlier verdict [9] that there is less variability of retinopathy than of macrovascular disease incidence among different diabetic populations. Incidence of any retinopathy varied approximately twofold and of PDR approximately threefold compared with the tenfold variation in some manifestations of macrovascular disease incidence observed in the WHO MSVDD [13]. This strongly suggests that whereas diabetic micro- vascular and macrovascular disease could share some common risk factors, other determinants could dominate the differential risks.

Although some of the variation in retinopathy incidence estimates was likely to have been attributable to the differences between observers at different centres and the relative imprecision of ophthalmoscopic ascertainment, reported incident retinopathy was clearly associated with several of the variables measured at baseline, in the group as a whole and within some individual centres. Baseline hyperglycaemia, raised arterial pressure and duration of diabetes (a proportion of it probably unrecognised) were risk factors for retinopathy incidence. Variable facilities for early diagnosis of diabetes, management of the disease, recognition of the appearance of retinopathy and detection and correction of the other risk factors are also likely to have contributed to differences in the outcome. Our findings support and reinforce other studies of the genesis and progression of diabetic retinopathy and emphasize the potential for systematic interventions to achieve earlier detection, better control and more effective correction of risk factors in the prevention of this disabling complication.

\section{References}

1. Jarrett RJ, Keen H, Grabauskas V (1979) The WHO Multinational Study of Vascular Disease in Diabetes: 1. General description. Diabetes Care 2: 175-86

2. National Society to Prevent Blindness (1980)Vision problems in the US. Data Analysis. Definitions, data sources, detailed data tables, analysis, interpretation. National Society to Prevent Blindness, New York, pp 1-46

3. Klein R, Klein BEK (1985) Vision disorders in diabetes. In: Harris MI, Hamman RF (eds) Diabetes in America. US Govt Printing Office, Washington DC pp XIII 1-33 (DHHS publ. no 85-1468)

4. Sorsby A (1973) The incidence and causes of blindness in England and Wales, 1963-1968. Report No. 128, Her Majesty's Stationery Office, London, pp 1-72

5. Houston A (1982) Retinopathy in the Poole area: an epidemiological inquiry. In Eschwege E (ed) Advances in diabetes epidemiology. INSERM Symposium no 22, Elsevier Amsterdam, pp 199-206

6. Uemura K, Pisa Z (1985) Recent trends in cardiovascular disease mortality in 27 industrialised countries. World Health Stat Q 38: 142-162

7. Robertson WB, Strong JP (1968) Atherosclerosis in persons with hypertension and diabetes mellitus. Lab Invest 18: 78-91

8. Jarrett RJ (1984) The epidemiology of coronary heart disease and related factors in the context of diabetes mellitus and impaired glucose tolerance. In: Jarrett RJ (ed) Diabetes and heart disease. Elsevier, Amsterdam, pp 1-23

9. West KM (1978) Epidemiology of diabetes and its vascular complications. Elsevier, New York, pp 407

10. Keen H, Jarrett RJ (1979) The WHO Multinational Study of Vascular Disease in Diabetes: 2. Macrovascular disease prevalence. Diabetes Care 2: 187-95

11. Jarrett RJ, Keen H (1979) The WHO Multinational of Vascular Disease in Diabetes: 3. Microvascular Disease. Diabetes Care 2: 196-201 
12. Diabetes Drafting Group (1985) Prevalence of small vessel and large vessel disease in diabetic patients from 14 centres. The World Health Organization Multinational Study of Vascular Disease in Diabetes. Diabetologia 28: 615-640

13. Lee ET, Keen H, Bennett PH, Fuller J, Lu M and the WHO Multinational Study Group (2001) Follow-up of the WHO Multinational Study of Vascular Disease in Diabetes: General description and morbidity. Diabetologia 44 [Supp 2]: S3-S13

14. Fuller J, Stevens LK, Wang S-L (1996) International variations in cardiovascular mortality associated with diabetes mellitus: The WHO Multinational Study of Vascular Disease in Diabetes. Ann Med 28: 319-322

15. Klein R, Moss SE, Klein BEK, DeMets DL (1989) Relation of ocular and systemic factors to survival in diabetes. Arch Intern Med 149: 266-272

16. Head J, Fuller J (1990) International variations in mortality among diabetic patients: the WHO Multinational Study of Vascular Disease in Diabetes. Diabetologia 33: 477-481

17. Harris MI (1993) Undiagnosed NIDDM: Clinical and public health issues. Diabetes Care 16: 642-652

18. Klein R, Klein BEK, Moss SE, Davis MD, DeMets DL (1984) The Wisconsin epidemiologic study of diabetic retinopathy. III. Prevalence and risk of diabetic retinopathy when age at diagnosis is 30 or more years. Arch Ophthalmol 102: 527-532

19. Haffner SM, Fong D, Stern MP et al. (1988) Diabetic retinopathy in Mexican Americans and non-Hispanic whites. Diabetes 37: 878-884

20. Dorf A, Ballintine EJ, Bennett PH, Miller M (1976) Retinopathy in Pima Indians: Relations to glucose level, duration of diabetes, age at diagnosis of diabetes, and age at examination in a population with a high prevalence of diabetes mellitus. Diabetes 25: $554-560$

21. Lienert RT (1989) Inter-observer comparisons of ophthalmoscopic assessment of diabetic retinopathy. Aust N Z J Ophthalmol 17: 363-368

22. Klein R, Klein BEK, Moss SE, Davis MD, DeMets DL (1989) The Wisconsin epidemiologic study of diabetic retinopathy; IX. Four-year incidence and progression of diabetic retinopathy when age at diagnosis is less than 30 years. Arch Ophthalmol 107: 237-243

23. Klein R, Klein BEK, Moss SE, Davis MD, DeMets DL (1989) The Wisconsin epidemiologic study of diabetic retinopathy; X. four-year incidence and progression of diabetic retinopathy when age at diagnosis is 30 years or more. Arch Ophthalmol 107: 244-249

24. Dwyer MS, Melton LJ 3rd, Ballard DJ, Palumbo PJ, Trautmann JC, Chu CP (1985) Incidence of diabetic retinopathy and blindness: A population-based study in Rochester, Minnesota. Diabetes Care 8: 316-322

25. Lee ET, Lee VS, Kingsley RM et al. (1992) Diabetic retinopathy in Oklahoma Indians with NIDDM: incidence and risk factors. Diabetes Care 15: 1620-1627

26. Nelson RG, Wolfe JA, Horton MB, Pettitt DJ, Bennett PH (1989) Proliferative retinopathy in NIDDM: incidence and risk factors in Pima Indians. Diabetes 38: 435-440

27. Knowler WC, Bennett PH, Ballintine EJ (1980) Increased incidence of retinopathy in diabetics with elevated blood pressure: A six-year follow-up study in Pima Indians. N Engl J Med 302: 645-650

28. Teuscher A, Schnell H, Wilson PWF (1988) Incidence of Diabetic retinopathy and relation to baseline plasma glucose and blood pressure. Diabetes Care 11: 246-251

29. Ballard DJ, Melton LJ 3rd, Dwyer MS et al. (1986) Risk factors for diabetic retinopathy: A population-based study in Rochester, Minnesota. Diabetes Care 9: 334-342

30. Moss SE, Klein R, Klein BEK (1991) Association of cigarette smoking with diabetic retinopathy. Diabetes Care 14: 119-126

31. West KM, Erdreich LS, Stober JA (1980) Absence of relation between smoking and diabetic microangiopathy. Diabetes Care 3: 250-252
32. Lee ET, Lee VS, Lu M, Russell D (1992) Development of proliferative retinopathy in NIDDM, a follow-up study of American Indians in Oklahoma. Diabetes 41: 359-367

33. Sjolie AK, Stephenson J, Aldington S et al. (1997) Retinopathy and vision loss in insulin-dependent diabetes in Europe. Ophthalmology 104: 252-260

34. Morrish NJ, Wang S-L, Stevens LK, Fuller J, Keen H and the WHO Multinational Study Group (2001) Mortality and causes of death in the WHO Multinational Study of Vascular Disease in Diabetes. Diabetologia 44 [Supp 2]: S 14-S 21

35. Davis MD, Hiller R, Magli YLM et al. (1979) Prognosis for life in patients with diabetes: relation to severity of retinopathy. Trans Am Ophthalmol Soc 77: 144-170

36. Harris CL, Chu H-H, Lawson K et al. (1993) Mortality of Mexican Americans with NIDDM. Retinopathy and other predictors in Starr County, Texas. Diabetes Care 16: 82-89

37. Klein R, Klein BEK, Neider MW et al. (1985) Diabetic retinopathy as detected using ophthalmoscopy, a non-mydriatic camera, and a standard fundus camera. Ophthalmology 92: 485-491

38. United Kingdom Prospective Diabetes Study Group (1998) UK Prospective Diabetes Study 30: diabetic retinopathy at diagnosis of Type II diabetes and associated risk factors. Arch Ophthalmol 116: 297-303

39. Klein R (1995) Hyperglycaemia and microvascular and macrovascular disease in diabetes. Diabetes Care 18: 258-268

40. Knatterud GL, Klimt CR, Levin ME et al. (1978) Effects of hypoglycemic agents on vascular complications in patients with adult-onset diabetes. VII Mortality and selected nonfatal events with insulin treatment. JAMA 240: 37-42

41. Hamman RF (1997) Epidemiology of microvascular complications. In: KGMM Alberti, PJ Zimmet, RA DeFronzo, H Keen (eds) International Textbook of Diabetes Mellitus, 2nd ed. John Wiley and Sons, New York pp: 1293-1319

42. Pirart J (1978) Diabetes mellitus and its degenerative complications: a prospective study of 4000 patients observed between 1947 and 1973. Diabetes Care 1: 168-188

43. Klein R, Klein BEK, Moss SE (1989) The Wisconsin epidemiological study of diabetic retinopathy: a review. Diabetes Metab Rev 5: 559-570

44. Richard P, Berglund B, Britz A, Cars I, Nilsson BY, Rosenqvist U (1991) Intensified conventional insulin treatment retards the microvascular complications of insulin-dependent diabetes mellitus (IDDM): the Stockholm Diabetes Intervention Study (SDIS) after 5 years. J Intern Med 230: 101-108

45. DCCT Research Group (1993) The effect of intensive treatment of diabetes on the development and progression of long-term complications insulin-dependent diabetes mellitus. N Engl J Med 329: 977-986

46. Ohkubo Y, Kishikawa H, Araki E et al. (1995) Intensive insulin therapy prevents the progression of diabetic microvascular complications in Japanese patients with non-insulin-dependent diabetes mellitus: a randomised prospective 6-year study. Diabetes Res Clin Pract 28: 103-117

47. UK Prospective Diabetes Study Group (1998) Intensive blood glucose control with sulphonylureas or insulin compared with conventional treatment and risk of complications in patients with type diabetes (UKPDS 33). Lancet 352: 837-853

48. UK Prospective Diabetes Study (1990) Complications in newly diagnosed Type II diabetic patients and their association with different clinical and biochemical risk factors. Diabetes Res 13: $1-11$

49. UK Prospective Diabetes Study Group (1998) Tight blood pressure control and risk of macrovascular and microvascular complications in Type II diabetes: UKPDS 38. BMJ 317: 703-713

50. Early Treatment Diabetic Retinopathy Study Research Group (1991) Early photocoagulation for diabetic retinopathy ETDRS Report 9. Ophthalmology 98 [Suppl 1]: 766-785 